Thorax (1969), 24, 112.

\title{
Aortitis presenting as mitral stenosis and aortic regurgitation
}

\author{
D. C. DUNN ANDS.C. LENNOX \\ From The Brompton Hospital, London, S.W.3
}

A case of non-specific aortitis with cardiac involvement presenting as severe mitral stenosis and aortic regurgitation is described, together with the evidence for this diagnosis.

Aortitis as a cause of aortic regurgitation is well recognized. It is unusual to see these lesions combined with mitral stenosis. The following case is reported and considered in relation to the literature.

\section{CASE REPORT}

The patient, a 36-year-old woman from Saudi Arabia, spoke no English but, through an interpreter, the following history was obtained.

Ten years previously she had had an episode of pain in the left elbow and knee but was said to be afebrile. Following this she had had recurrent attacks of breathlessness and palpitations.

Three years ago she was investigated, including a full cardiac study at Beirut. The results of these tests were not available before operation. We later learned that she had had the signs of mitral stenosis and that her blood pressure had varied between $220 / 0$ and $180 / 20 \mathrm{~mm}$. Hg. A block in the left subclavian artery had been demonstrated at aortography. Her sedimentation rate was $95 \mathrm{~mm} . / \mathrm{hr}$ and the white blood cell count $14,000 / \mathrm{cu}$. mm., of which $81 \%$ were neutrophils, $17 \%$ lymphocytes, and $2 \%$ monocytes. Over the past three years she had complained of increasing breathlessness on exertion, associated with palpitations and, more recently, chest pain. Two months previously, while on a pilgrimage to Mecca, she became acutely ill and was admitted to hospital. In the past few weeks she had had attacks of nocturnal dyspnoea. There was no history of embolic episodes or arterial insufficiency in the limbs.

On examination she weighed $41.75 \mathrm{~kg}$. and her height was $147.5 \mathrm{~cm}$. She was afebrile. She was thin and had a high arch palate, but there was no evidence of arachnodactyly, clubbing, or cyanosis. A long scar was present over the right brachial artery and a small scar over the right femoral artery from the previous cardiac catheterization. Examination of the fundi showed a clear lens and marked retinal arterial pulsation. She had a collapsing pulse in the vessels of the right arm, left leg, and both carotids, but a small pulse in the left arm and right leg. Systolic murmurs were heard over both carotids, the right subclavian, and the left iliac arteries. Her pulse was regular and $c$ the blood pressure was $190 / 0 \mathrm{~mm}$. $\mathrm{Hg}$ in the right arm and $105 / 65 \mathrm{~mm}$. $\mathrm{Hg}$ in the left arm. The jugular venous pulse was raised $2 \mathrm{~cm}$. above the sternal angle with a normal wave form. There was a loud first $\vec{\varphi}$

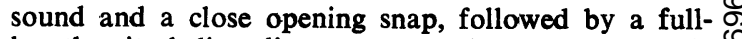
length mitral diastolic murmur at the apex. An aortic systolic murmur was conducted into the neck and a loud early diastolic murmur was present along the left sternal edge. Examination of the abdomen revealed no ascites, but the liver was felt one fingerbreadth below the costal margin and the spleen two $\stackrel{\circ}{\Phi}$ fingerbreadths.

INVESTIGations Chest radiography (Figs 1 and 2) showed an enlarged left atrium with a prominent appendage, left ventricle, and pulmonary artery. The upper lobe veins were prominent and septal lines were present. The thoracic spine appeared normal. The $\underline{\partial}$ electrocardiogram (Fig. 3) showed sinus rhythm, left axis deviation, left atrial hypertrophy and left ventricular hypertrophy.

The haemoglobin was $82 \%$ and white cells $10,000 /$ cu. mm., of which $51 \%$ were neutrophils, $26 \%$ lymphocytes, and $15 \%$ eosinophils. The sedimentation rate was $50 \mathrm{~mm}$./hour. The Wassermann reac- 을 tion, Price precipitation reaction, Reiter's precipitin complement fixation, and Treponema immobilization tests were all negative, as was the Paul-Bunnell and Salmonella and Brucella antibody tests. The electro- o lytes were normal, the blood urea $33 \mathrm{mg} . / 100 \mathrm{ml}$., and N examination of the urine was normal.

The patient clearly had severe mitral stenosis and $\omega$ aortic regurgitation, but the changes in the peripheral ${ }_{2}$ pulses were unexplained. At the time, the most likely 6 cause was thought to be peripheral embolization.

PROGRESS Four days after admission she had a 0 severe attack of pulmonary oedema which required intensive therapy. Her condition at this stage was too $\vec{D}$ poor to justify further cardiac studies and it was

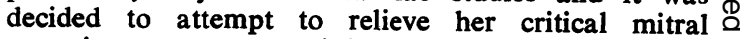
stenosis as soon as possible, and at the same time to replace her aortic valve. 


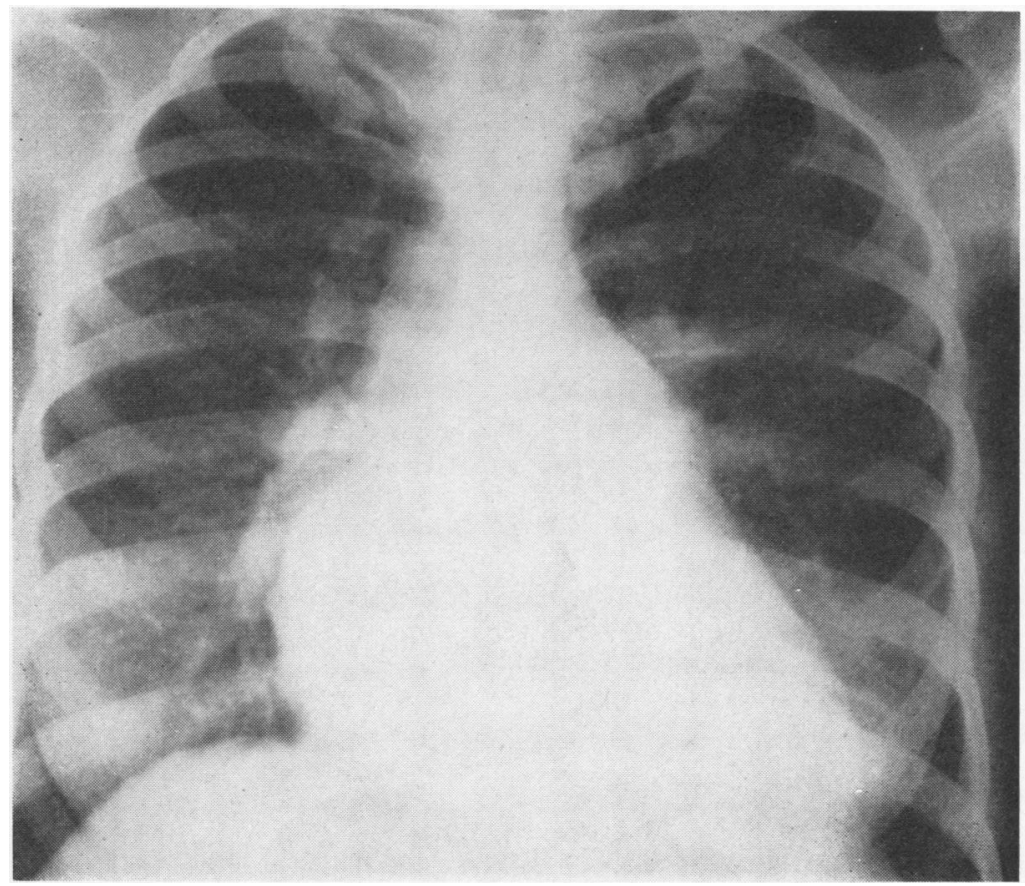

FIG. 1. Postero-anterior chest radiograph.

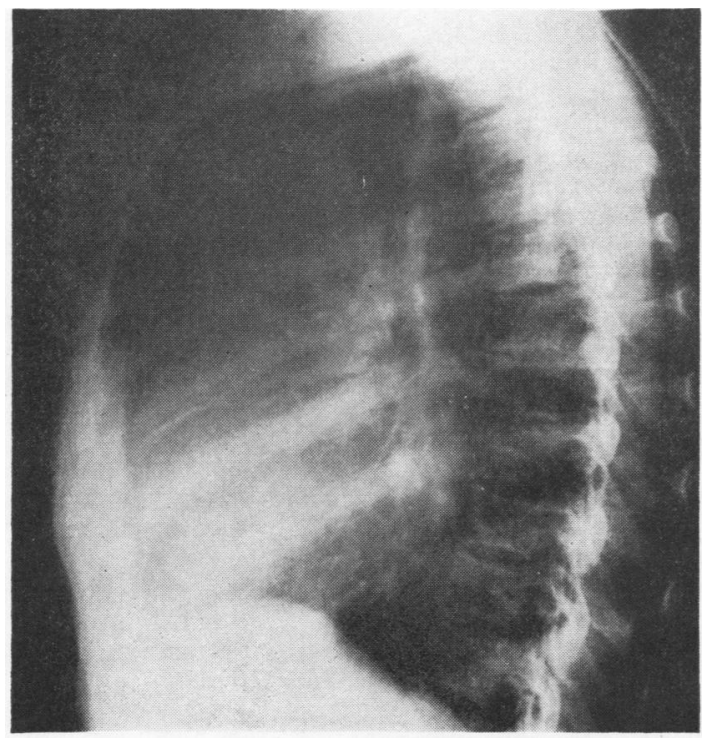

FIG. 2. Left lateral chest radiograph.
OPERATION A median sternotomy incision was made. On opening the pericardium, the ascending aorta was found to be enlarged and grossly thickened. It was adherent to the surrounding structures and compressed the pulmonary artery and the superior vena cava. The local conditions appeared unfavourable for replacement of the aortic valve. At this stage her general condition, which had never been good, deteriorated further and cardiac massage was needed to support the circulation. While a closed mitral valvotomy was being done, ventricular fibrillation developed, and normal rhythm could not be restored. Before the valvotomy, the valve orifice was assessed at $1.5 \mathrm{~cm} . \times 1 \mathrm{~cm}$.

\section{NECROPSY}

Heart There was marked left ventricular hypertrophy (Fig. 4). The mitral valve cusps were thickened and opaque. The chordae were normal. There was no stenosis at this time. The tricuspid valve was normal. The pulmonary valve was normal. The aortic valve cusps were thickened and opaque. There was no calcification. The aortic ring was dilated, and there was aneurysmal dilatation of the ascending aorta. The intima was smooth and white in appearance. The 


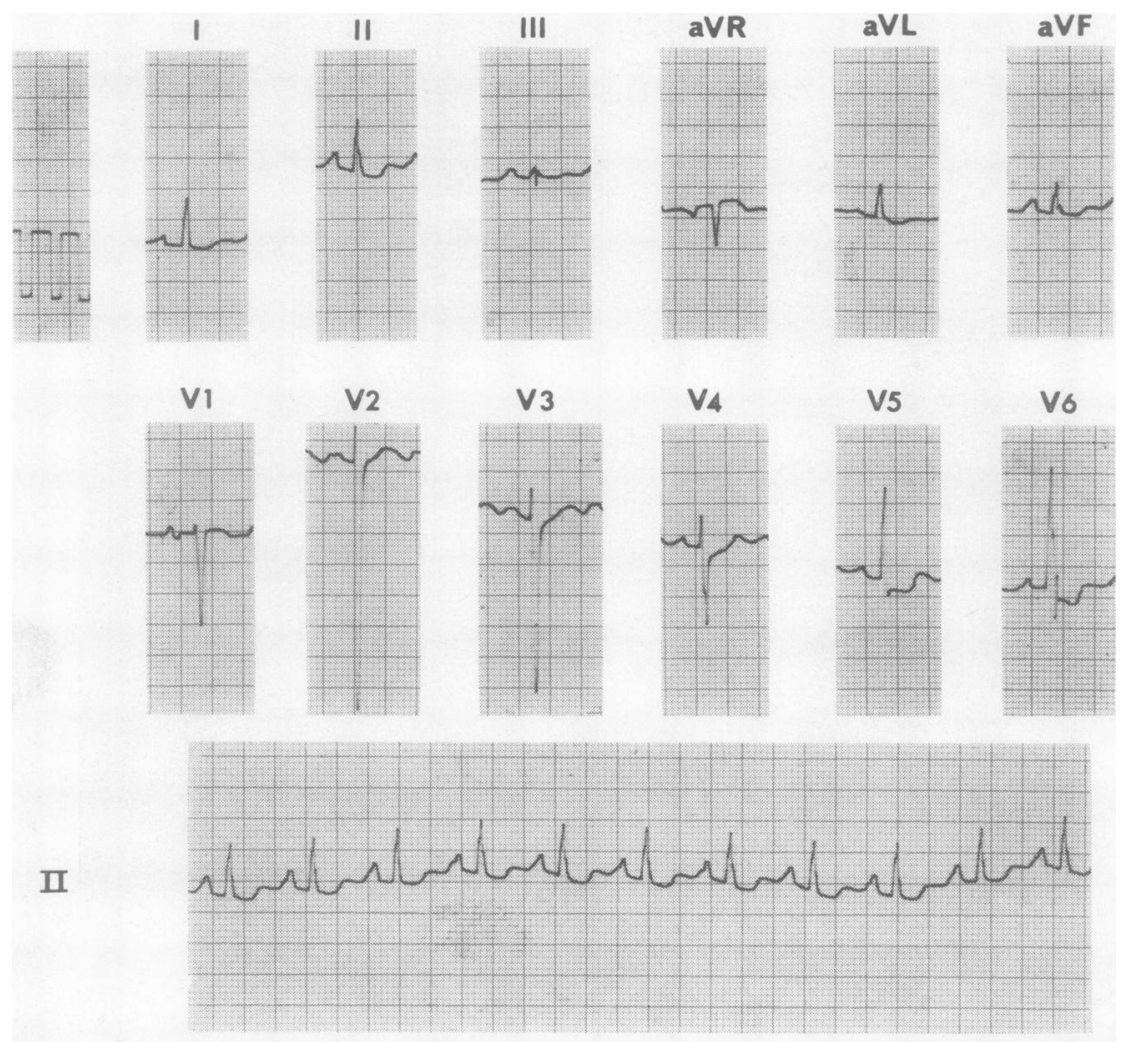

$13 \cdot 2 \cdot 67$

FIG. 3. Electrocardiogram.

first parts of the great vessels were narrowed by thickening of their walls. This change was most marked in the left subclavian, the lumen of which was reduced to about $2 \mathrm{~mm}$. The coronary vessels were normal. The pulmonary artery was also thickened.

Lungs The trachea and major bronchi were normal. There were filmy adhesions over the left lower lobe.

Abdomen There was a small amount of clear ascitic fluid. The liver was grossly enlarged by congestion. The spleen was enlarged $\times 4$ and deeply congested. The kidneys showed some congestion. The renal arteries were normal.

The skull, brain, thyroid, gut, and suprarenals were normal.

The cerebral vessels were normal.

\section{HISTOLOGY}

Aorta (Fig. 5) The thickening of the ascending aorta was mainly due to a dense layer of hyaline fibrous tissue in the outer part of the wall. In many areas there was a zone of chronic granulomatous inflammation between the thickened adventitia and the media. This zone contained many plasma cells, some with Russell bodies, together with macrophages and occasional multinucleate giant cells. Most of the vasa vasorum in this region showed obliterative endarteritis. Occasional foci of necrosis in this zone extended through the media into the intima. The media was thinned due to destruction of its outer part. The intima was thickened and deposits of platelet thrombus were seen on its surface. The collagenous thickening of the aortic root could be seen to extend in to the aortic valve cusps and was continuous with the scarring in the mitral valve (Fig. 6).

Abdominal aorta The changes were similar to those of the thoracic aorta but with even more destruction of the media.

Left subclavian artery (Fig. 7) This showed a thick mantle of acellular collagen and thinning of the media. The intima was also thickened.

Heart The myocardium was normal. There were no Aschoff bodies. The mitral valve leaflets showed 


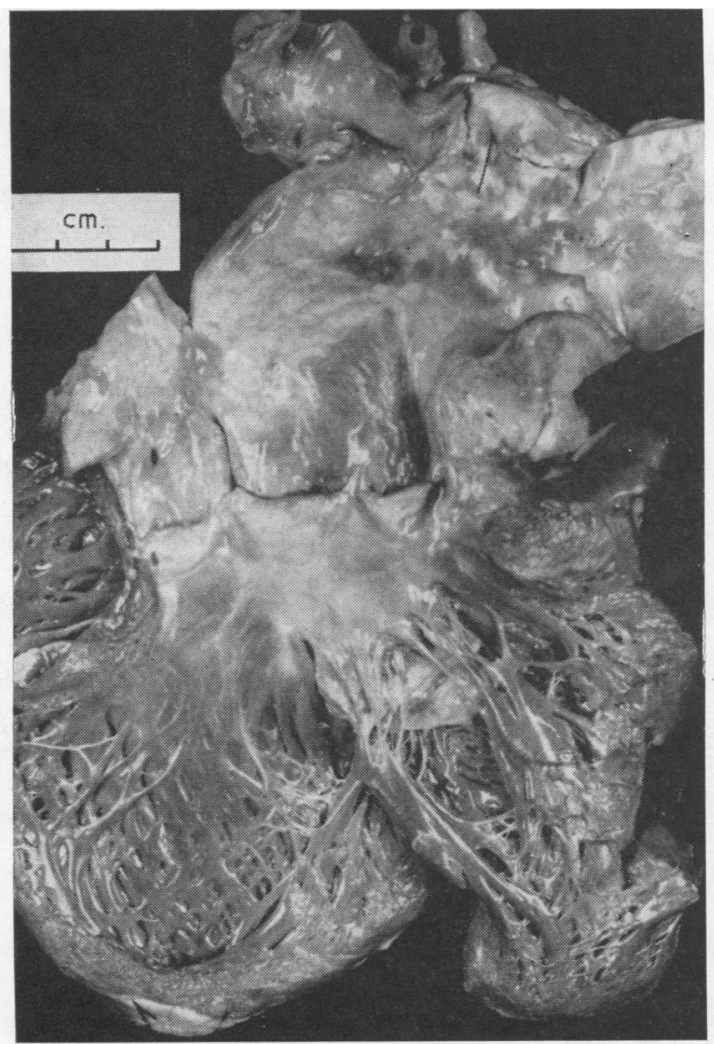

FIG. 4. A view of the heart displaying the left ventricle and aorta. Note the probe in the left subclavian artery, and the thickened left carotid and innominate arteries. The cusps of the aortic and mitral valves are thickened, although the chordae tendineae are normal.

collagenous thickening, but no active inflammatory process was seen. The coronary arteries were normal.

Lungs There was an excess of eosinophils in the bronchial walls. The bronchial vessels were normal. There was mild parenchymal congestion.

Spleen A number of plasma cells were scattered through the pulp. There was also an excess of eosinophils. There was moderate general congestion.

Kidneys The kidneys, including the renal artery, were normal.

CONCLUSION The vascular changes, which were confined to the aorta and its major branches, were those of non-specific aortitis. They were in continuity with the changes in the aortic and mitral valves.

\section{DISCUSSION}

Non-syphilitic arteritis of the aorta and its major branches is becoming increasingly recognized. This chronic inflammation may attack any part of the aorta or great vessels, giving rise to the macroscopic changes of thickening of the vessel wall with either narrowing of the lumen or aneurysm formation. A variety of clinical presentations may result. When the aortic arch is involved symptoms of cerebrovascular insufficiency, facial weakness, ocular disturbances, or upper limb ischaemia are produced. Disease of the abdominal aorta may result in abdominal symptoms or hypertension, while intermittent claudication can be produced by occlusion of the distal

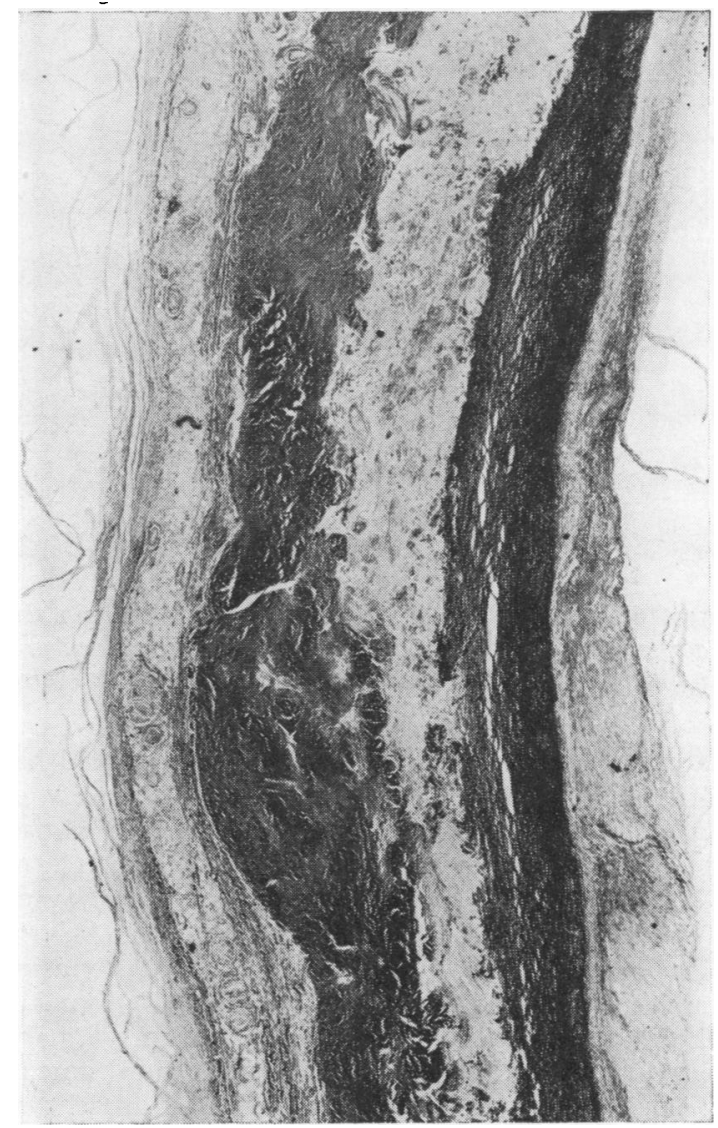

FIG. 5. Aortic arch $\times 10$. This shows moderate intimal thickening, thinning of the media, and gross adventitial thickening. A pale staining band of granulation tissue is sandwiched between the dark band of the media and the dense collagenous tissue of the adventitia. 


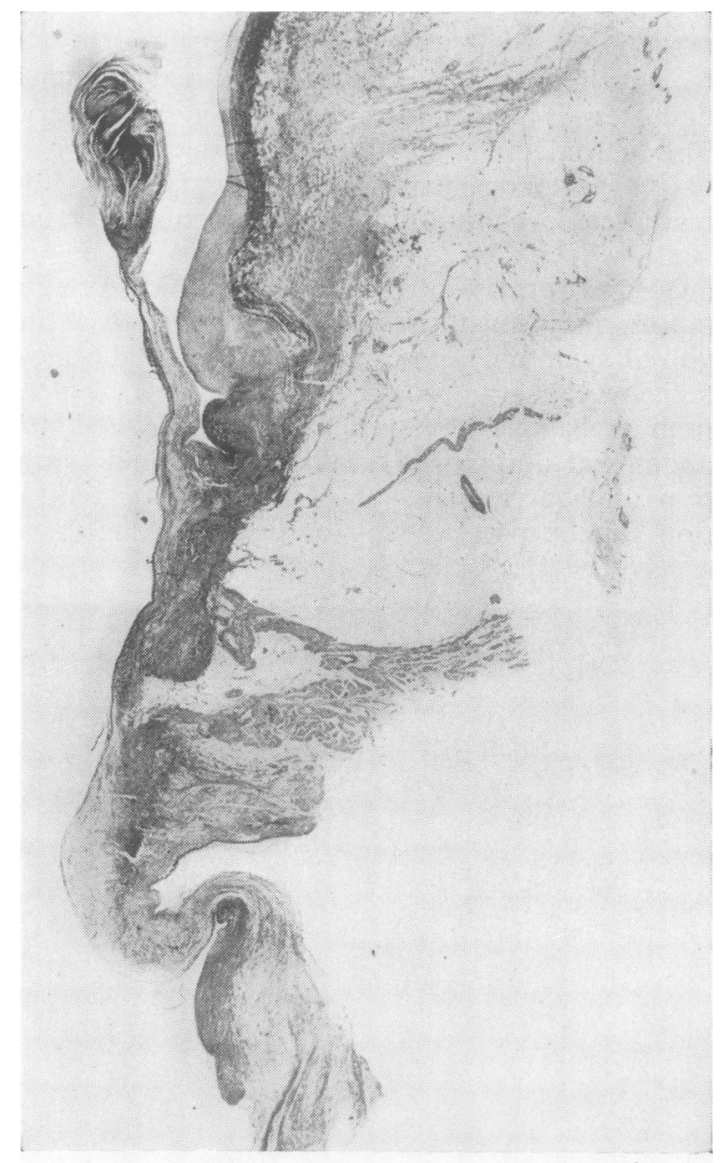

FIG. 6. Root of aorta including aortic valve cusp and aortic cusp of mitral valve. The collagenous thickening of the aortic wall is continuous with that in the mitral valve.

aorta. The diverse nature of lesions produced has led to its being called by a confusing variety of names. Among these are reversed coarctation (Giffin, 1939), pulseless disease (Shimizu and Sano, 1951), Takayashu's disease (Caccamise and Whitman, 1952), subisthmic coarctation (Morris, De Bakey, Cooley, and Crawford, 1960), stenosing aortitis (Sen, Kinare, Kulkarni, and Parulkar, 1962), middle aortic syndrome (Sen, Kinare, Engineer, and Parulkar, 1963), and central aortitis (Asherson and Gordon, 1964). In all these syndromes there is a chronic inflammation in part, or all, of the aorta and great vessels.

Similar histological changes of inflammatory disease of the aorta are seen in other diseases. In one, syphilitic aortitis, the aetiology is well established. In the remainder no causative agent has been found. These include cases in which the aortitis has been associated with a recognized $\frac{}{\circ}$ disease process itself of unknown aetiology, e.g., $\overline{\bar{\rho}}$. rheumatoid arthritis (Heggtveit, Hennigar, and $\vec{\Phi}$ Morrione, 1963 ; Clark, Kulka, and Bauer, 1957), ankylosing spondylitis (Crow, 1960), and dissem- $-\infty$ inated lupus erythematosus (Miller, Thomas, and $\vec{\circ}$ Medd, 1962). When aortic inflammation has beenfound with no evidence of other disease, the term $\vec{\omega}$ 'non-specific' aortitis has been used. We believe $\overrightarrow{\overrightarrow{\vec{x}}}$ our case to belong in the latter group.

Cardiac involvement has been reported in association with non-specific aortitis. McGuire,-Scott, and Gall (1958) described five cases with $\overrightarrow{\vec{\sim}}$ aortic regurgitation, and in two of these there was slight thickening of the mitral valve with shorten- -5 ing of the chordae tendineae found at necropsy. $\vec{c}$ Schrire and Asherson (1964) reported 18 cases of aortitis seen in a cardiac clinic over 11 years and found cardiac involvement in eight of them. They stated that the heart might be affected by $\overrightarrow{0}$ (1) aortic valve involvement, (2) coronary artery 8 involvement, (3) hypertension secondary to renal artery disease, and (4) direct involvement of the

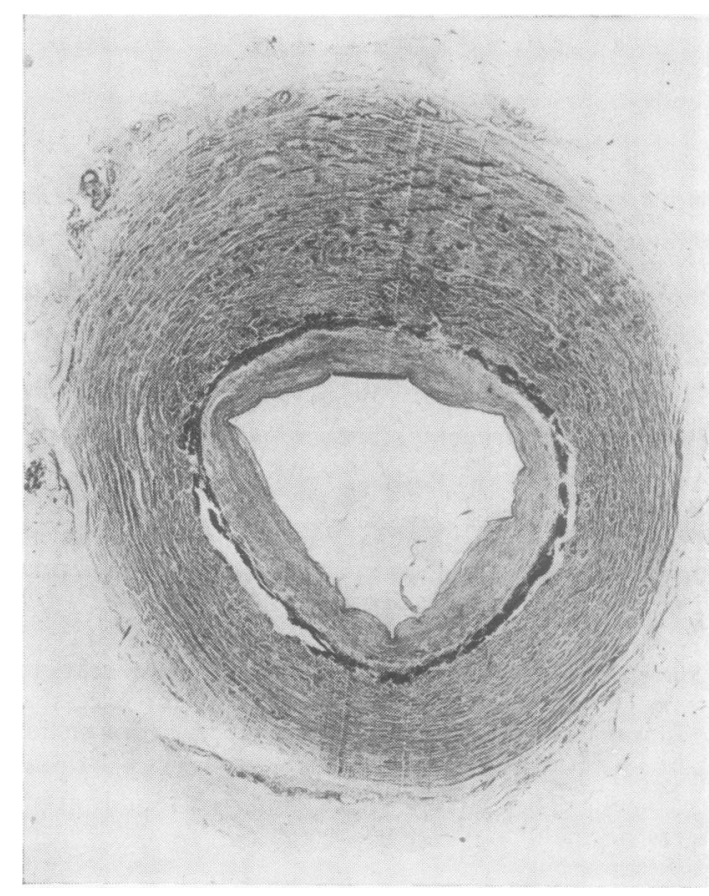

FIG. 7. Left subclavian artery showing thick mantle of acellular collagen and thinning of media (black). The intima is also thickened. 
cardiac muscle. Six of their patients had aortic valve disease and three also had mitral regurgitation secondary to ventricular dilatation. None had mitral stenosis.

In our case, the presenting condition was critical mitral stenosis. Clinically, this might have been of rheumatic origin in that she had had a febrile illness with joint pains 10 years before. There was no histological support for this as a separate diagnosis and the appearance of the chordae was against it (Fig. 4). We believe that the mitral stenosis was due to the same inflammatory process seen in the aorta and aortic valve cusps, the fibrosis in all three areas being in continuity (Fig. 6). Ansell, Bywaters, and Doniach (1958) predicted that mitral valve involvement might occur in cases of aortitis and ankylosing spondylitis. Many cases of aortitis have been associated with a prior attack of a 'rheumatic' illness (Sandring and Welin, 1961).

In many respects this case resembles other cases of non-specific aortitis. These include the fact that the patient was a young woman at the onset of the disease and that she had a raised E.S.R., a moderate leucocytosis, and a mild anaemia. In addition, she had eosinophilia in the peripheral blood, spleen, and bronchial muscles. While this may be unconnected with the aortitis, it remains of interest while so little is known of the aetiology of this disease.
We wish to thank for their help and encouragement Lord Brock, under whose care this patient was admitted, and Dr. K. F. W. Hinson and Dr. A. G. Stansfeld, who interpreted the pathology.

\section{REFERENCES}

Ansell, B. M., Bywaters, E. G. L., and Doniach, I. (1958). The aortic lesion of ankylosing spondylitis. Brit. Heart J., 20, 507 .

Asherson, R., and Gordon, H. (1964). A case of idiopathic central arteritis. S. Afr. med. J., 38, 751 .

Caccamise, W. C., and Whitman, J. F. (1952). Pulseless disease: a preliminary case report. Amer. Heart J., 44, 629.

Clark, W. S., Kulka, J. P., and Bauer, W. (1957). Rheumatoid aortitis with aortic regurgitation. Amer. J. Med., $22,580$.

Crow, R. S. (1960). Aortic incompetence in ankylosing spondylitis. Brit. med. J., 2, 271.

Giffin, H. M. (1939). Reversed coarctation and vasomotor gradient: report of a cardiovascular anomaly with symptoms of brain tumor. Proc. Mayo Clin., 14, 561.

Heggtveit, H. A., Hennigar, G. R., and Morrione, T. G. (1963). Panaortitis. Amer. J. Path., 42, 151.

McGuire, J., Scott, R. C., and Gall, E. A. (1958). Chronic aortitis of undetermined cause with severe and fatal aortic insufficiency. Amer. J. med. Sci., 235, 394.

Miller, G. A. H., Thomas, M. L., and Medd, W. E. (1962). Aortic arch syndrome and polymyositis with L.E. cells in peripheral blood. Brit. med. J., 1, 771.

Morris, G. C., Jr., De Bakey, M. E., Cooley, D. A., and Crawford, E. S. (1960). Subisthmic aortic stenosis and occlusive disease. Arch. Surg., 80, 87.

Sandring, H., and Welin, G. (1961). Aortic arch syndrome with special reference to rheumatoid arteritis. Acta med. scand., 170 , 1.

Schrire, V., and Asherson, R. A. (1964). Arteritis of the aorta and its major branches. Quart. J. Med., 33, 439.

Sen, P. K., Kinare, S. G., Engineer, S. D., and Parulkar, G. B. (1963), The middle aortic syndrome. Brit. Heart J., 25, 610.

Kulkarni, T. P., and Parulkar, G. B. (1962). Stenosing aortitis of unknown etiology. Surgery, 51, 317.

Shimizu, K., and Sano, K. (1951). Pulseless disease. J. Neuropath clin. Neurol., 1, 37 . 